Meta

Journal des traducteurs

Translators' Journal

\title{
An Alternative Instructional Model: Teaching Medical Translation Online
}

\section{María Asuncion Gómez et Steven Weinreb}

Volume 47, numéro 4, décembre 2002

URI : https://id.erudit.org/iderudit/008044ar

DOI : https://doi.org/10.7202/008044ar

Aller au sommaire du numéro

Éditeur(s)

Les Presses de l'Université de Montréal

ISSN

0026-0452 (imprimé)

1492-1421 (numérique)

Découvrir la revue

Citer cette note

Asuncion Gómez, M. \& Weinreb, S. (2002). An Alternative Instructional Model: Teaching Medical Translation Online. Meta, 47(4), 643-648.

https://doi.org/10.7202/008044ar
Résumé de l'article

Traditionnellement, on a enseigné la traduction des textes médicaux dans des salles de cours avec un support technique limité. Nous présentons nos expériences en enseignant avec l'Internet dans ce domaine de la traduction assez spécialisé. Notre expérience est dans le contexte d'un programme universitaire de traduction et d'interprétation. Nous présentons le modèle d'enseignement et la structure du cours avec nos idées sur le rôle de l'enseignement connecté dans la formation des traducteurs modernes. 


\section{BLOC-NOTES}

\section{An Alternative Instructional Model: Teaching Medical Translation Online}

\begin{abstract}
RÉSUMÉ
Traditionnellement, on a enseigné la traduction des textes médicaux dans des salles de cours avec un support technique limité. Nous présentons nos expériences en enseignant avec l'Internet dans ce domaine de la traduction assez spécialisé. Notre expérience est dans le contexte d'un programme universitaire de traduction et d'interprétation. Nous présentons le modèle d'enseignement et la structure du cours avec nos idées sur le rôle de l'enseignement connecté dans la formation des traducteurs modernes.
\end{abstract}

\begin{abstract}
Teaching medical translation has traditionally been performed in classrooms with limited use of technical advances. We report our experiences in the teaching of this translation specialty via the use of the Internet within the context of a university-based translation and interpretation program. The teaching model and course structure are presented along with our suggestions for the role of distance learning in the educational process for modern translators.
\end{abstract}

\section{MOTS-CLÉS/KEY WORDS}

Medical translation, WebCT, online courses, teaching

\section{INTRODUCTION}

In the new millennium, both the role of the teacher and the classroom environment are undergoing a radical process of transformation as universities seek to expand their student base, conserve precious campus resources and continue to provide high quality education. As the Internet becomes more widely available at institutions both large and small, distance education is now gaining momentum, providing educators with the tools that will successfully bridge the gap between instructor and learner in space and/or time. The traditional teaching environment is still important, but incursions by the virtual classroom ("electronic university," "e-learning") are becoming a way of life for many universities. ${ }^{1}$ This terminology refers to the teaching of courses, partially or completely, via the Internet ("World Wide Web," "the Web") and is directly related to the concept of self-directed learning (Brookfield, 1993).

Both translators and educators face new issues and challenges in the theory and practice of translation. The teaching of translation has long been felt to require a "personalized" type of instructorstudent interaction, with the use of standard classroom to present translation theory and facilitate the active discussion of difficult texts. Specialized areas of translation, such as commercial, technical, and medical translation, have been taught in the same fashion, as elective courses for the more advanced student. Few institutions have experimented with alternate forms of translation teaching, despite the ever-increasing exposure of translators to technological advances in their daily work. Modern translators, although they still make extensive use of dictionaries and glossaries, must also take advantage of other resources. They need computer and research skills that will help them bridge the transition to the digital environment as they confront the challenges of the workplace.

We should not be deluded into thinking that the mere use of technology will benefit all students. In order to provide our students with a successful learning experience, new pedagogical approaches are needed. One of the precepts of teaching in general is that pedagogy must drive the technology and not vice versa. Technology is an important tool, but as with any tool, it is useful only if one knows how to use it advantageously. We do not propose the use of technology simply because it is available, but because we firmly believe that it suits our particular needs and helps reach the goals of a specific course. Therefore, before we think about "how" we are going to teach a course online, it is useful to consider "why" it is a good idea. In the following pages we will describe our experience teaching a course on EnglishSpanish Medical Translation online, using a specific Web-based teaching platform (WebCT). We will discuss both the "why" and the "how" of this pioneering endeavor in the field, along with suggestions for improvement.

\section{WHY WEB-BASED DELIVERY?}

Anne Keating and Joseph Hargitai remind us in The Wired Professor that "the rationale for using the World Wide Web to deliver course material, as well as to promote classroom interaction, rests in the potential that this technology has for providing twenty-four-hour access to information from any computer connected to the Internet" (ix). While this is certainly the main advantage of webbased delivery, when thinking about our course on Medical Translation, we saw that the potential of teaching such a course online would fall under 
three major categories: student-related issues, delivery of instruction, and management of course information flow. As with any new teaching method, there are benefits for students, instructors and the university, although these may occasionally conflict as economic issues unavoidably come into play.

\section{Student-Related Issues}

Learning can take place without an instructor, without a textbook, and without a classroom. However, it cannot take place without students. That is why student-related issues are, in our opinion, crucial in curriculum development. We are summarizing below some of the main aspects that we considered before deciding to teach this course online.

1. Student Expectations. In the last few years, we have observed that, increasingly, our students have become computer literate and, to a certain degree, expect some degree of computer-mediated instruction.

2. Asynchronous Learning. Asynchronous participation in the course is an ideal solution for commuter universities where there is a high demand of courses that can be taken "any time-any place."

3. Self-motivation. Many of our students are working adults who want to acquire, or perfect, their translation skills. In general, they are highly motivated to work on their own and many of them prefer a model of on-demand, self-paced learning. ${ }^{2}$

4. Students' Interaction. Although there is not a face-to-face interaction, students communicate through chats, e-mail, and discussion forums. In theory, this written communication can go more in-depth than the oral remarks that can be exchanged in the classroom. When faced with a translation problem, students can research and think about it before giving an answer.

5. Student Recruitment. Medical Translation is a very specialized course that is taught only in very few universities. By offering it online, we have the potential of reaching students from all over the world. A diverse student population will bring a wealth of both linguistic and cultural experiences that will enhance the translation course. For the university, this means an expansion of the student base with only a minimal expenditure of resources, provided that the appropriate infrastructure and support personnel are available. As the course matures, it can be made available to other institutions without geographic limitations.

\section{Delivery of Instruction}

1. Avoiding the Printed Course Pack. Since there is no textbook on medical translation available yet, when we taught this course in the traditional face-to-face environment all the materials were photocopied. With the online course, lecture notes, articles and assignments are posted on a regular basis and the course can be tailored to the needs of each individual group of students. A course pack is cumbersome and gives less flexibility for change.

2. Access to Online Resources. Links to appropriate web sites are an invaluable tool for students working on Medical Translation. Glossaries and dictionaries can now be found online and are continuously updated. For more complicated translations, students can search for parallel texts on the Internet by viewing international web sites. Detailed technical information that will assist in the translation of technical information on pharmaceutical products and biomedical devices can be found by directly viewing documents from manufacturers.

3. Online Discussion Forums. These forums are ideal for ongoing discussion of translation problems posed by different assignments. They exist in the professional translators' world and students should become familiar with participating in them. ${ }^{3} \mathrm{~A}$ discussion forum is also a good pedagogical tool. Students will soon realize that many of the translation challenges cannot be dealt with relying exclusively on dictionaries. Medical language is constantly changing and incorporating many neologisms and this makes most specialized dictionaries outdated (especially bilingual ones) sometimes before they reach the public. It is the translators' job to search for solutions and defend a particular approach to translating a specific phrase or term that is not found in the dictionaries.

\section{Management of Course Information Flow}

1. Online Course Materials. Through the use of online course materials, students have permanent and instantaneous access to all of the important parts of the course: online syllabus, lesson schedule, course content materials, useful links, bulletin boards and electronic mail. The course may be continuously revised as the semester progresses in order to tailor it to the needs of the students. Rather than presenting all the materials at once, new modules must be posted periodically in order to assure an adequate level of student interest 
and to avoid overwhelming them with excessive information. This will also give the instructor added flexibility since materials may need to be redesigned as the course is in progress in order to better adjust to the level of student skills and the progress demonstrated by the initial assignments.

2. Online Grade Book. The online grade book allows students to check their grades and progress in the course at any time. Numerical grades for assignments are posted to the web pages, but professors can also periodically post progress reports. The flow of course information is not static and can be changed on a daily basis if necessary. When students "log on" to the course, they are presented with a calendar view so that they will be aware of changes that have occurred since their last visit.

\section{DESCRIPTION, ORGANIZATION, AND EVALUATION OF THE COURSE EXPERIENCE}

The Department of Modern Languages at Florida International University offers a Certificate Program in Translation and Interpretation Studies, and the Medical Translation course is one of the advanced electives within that program. It is also available to any interested matriculated or nonmatriculated university student. Medical Translation is offered once a year, and in the past the course has been taught in the conventional classroom. The department decided to offer this course via the Internet as a pilot project in an attempt to expand the student base and gain experience with this novel teaching method.

\section{WebCT: An Interactive Platform.}

The format for web-based instruction is based on the WebCT interactive platform that has been selected as a university-wide application at our institution. This product was initially developed at the University of British Columbia in Canada, and is now commercially available for implementation on various scales to accommodate large student bases and different styles of teaching. At our institution, WebCT permanently resides on dedicated servers housed on campus, but the program can be accessed by any student with a standard computer, dial-up modem, and Internet service. Support staff consists of technicians, responsible for the actual maintenance of the computers and data backup, and a group of technical advisors who are available to provide faculty training both at seminars and on an individual basis.

\section{Student Registration and Access to the Course.}

The course is listed as a "web-based" course with the same university course identification number as the previously taught "live course." Students register in the normal fashion and this registration information is then transferred from the Registrar to the Information Resource Management center, which then uploads the registered students into the WebCT course so that they appear on course rolls. Students cannot "self-register" but the instructor can give "guest" access to individuals who wish to observe the teaching process and access course materials. Each student is given a universal user name and initial password in order to access the course web pages, with the ability to subsequently change the password at their own convenience. If the student is taking more than one web-based course, they will employ the same user name for all courses. The initial page that the student views will list all courses for which they are currently registered along with any new information related to those courses.

Students are expected to have access to an Internet connection and standard Web browser as well as a personal computer with a word-processing program such as Microsoft Word. However, they may be unfamiliar with some of the specific techniques required to use WebCT and the teaching staff must be prepared to assist students during the initial one or two weeks of the course. Several optional on-campus learning sessions were offered to all interested students at the beginning of our course, and the majority of the students opted to attend these meetings.

\section{Course Organization and Structure}

Our Medical Translation pilot course was created to be fully web-based: students performed all of their translation assignments and readings at home. ${ }^{4}$ WebCT consists of a set of standardized "tools" which must be modified by the course designer. The instructor has great flexibility in course organization and design once the basic concepts are mastered. ${ }^{5}$ The principal component tools used for the Medical Translation course were the following: course home page, course calendar, content modules, assignment listing, course glossary, bulletin boards or forums, internal course electronic mail (e-mail), and course electronic grade book.

1. Home Page: The initial course web page that the student views upon successful login and it serves as an organizational center or "homeroom" for the course. The home page contains links to all of the remaining course pages and tools, and the student can return to it at any time during a web session. 
2. Course Calendar: All assignments and changes to the course are posted first to the calendar, which can also be linked to content pages. The calendar is set to "open" automatically and list any new entries that have appeared since the student's last web session.

3. Content Modules: These pages form the basis of the course learning blocks and can be viewed by the student in outline form or fully expanded. ${ }^{6}$ They have been subdivided into several sections that contain didactic information, reading material, and links to external web pages.

4. Assignment Listing Area: A large component of the student's grade is based upon successful completion of the translation assignments. Each week students are given two translation assignments (Spanish to English, English to Spanish), which are listed, in a separate area of the course. The assignment contains a word processor document, which must be downloaded by the student. After completion of the assignment, the student must return to the assignment listing area in order to upload the assignment for grading; when the assignment has been graded, the student may return again to view the grade. Students were expected to return the completed assignment within one week, but frequently they were unable to comply with this restriction. Although WebCT allows the instructor to reject the delivery of late assignments, this capacity was not utilized for the purposes of this course. After submitting the assignment, each file was then downloaded to the instructor's computer and reviewed. Comments and corrections were made using the editorial/reviewing functions of the word processor (in this case Microsoft Word for Windows), which allows the student to see the additions in a different color. After grading the assignment, the word processor file was then mailed back to the student as an email attachment. The student is able to view the grade at any time after it is entered into the electronic grade book.

5. Course Glossary: The searchable glossary is maintained by the instructor, and entries may be added at any time. Difficult terms and abbreviations are placed in the glossary that serves as an on-line "dictionary" for the students. While it is not designed to function as a medical Spanish-English bilingual dictionary, terminology from the assignments may be added periodically.

6. Bulletin Boards (Forums): Both students and instructors have access to the bulletin boards, which allow all participants to post discussion material and view the responses. The subject matter for discussion generally includes translation terminology, the Internet, technical issues specific to the course, and presentation of new or interesting web links that may be used as research tools.

7. Internal Course Electronic Mail: Each registered student is automatically assigned an internal e-mail address, which functions solely within the confines of the specific course. This type of internal process allows the instructor to return assignments with comments and corrections by means of document attachments, and also permits direct student communication with the instructor at any time. Timely responses to student messages is essential for the course to function properly, which may occupy a significant amount of instructor time as the course progresses and students become more accustomed to this type of interaction with the professor. The course e-mail provides an individualized experience to the students and is an integral part of the course operation.

8. Electronic Grade Book: Upon registration, the student is entered into the electronic grade book, which maintains a listing of all grades received for assignments and quizzes, and which has the capacity to perform mathematical calculations on this data for statistical and grading purposes. Each new assignment automatically appears as a new grading data column when it is listed in the assignment area, and the instructor may add new columns that correlate with additional assignments and examinations. At the end of the course, a grade is obtained from the numerical data derived from the electronic grade book, with an instructor "override" capability. WebCT allows the instructor to monitor student activity by indicating the number of times that they have entered the course pages and which pages they have read ("hits"); this information can also be used as part of the grading process.

\section{Students' Challenges and Evaluation of the Course}

Overall the comments from the students at the end of the course were positive. Most of them felt that the experience was useful, and that not only did they advance their translation skills, but were also much more skilled in terms of computer technology and their abilities to perform Web searches and obtain information via the Internet. A few students would have preferred the standard classroom type of interaction with face-to-face interaction with the instructors, yet admitted that the ability 
to perform their tasks at home and at their own pace far outweighed the potential disadvantages. Thus asynchronous learning was felt to be a major advantage of the web-based translation course.

Students who felt uncomfortable using the Internet had initial difficulties in mastering the course navigation system (home page, content modules, assignment area), but we found that the majority was able to learn these skills and felt comfortable with the course format within a reasonable period of time. The assignment area provided the main technical challenges to the students, since each assignment must be downloaded, translated and then uploaded in a precise fashion in order to be viewed by the instructor. Students initially tried to circumvent these steps by sending e-mail attachments, but this was not permitted since only assignments submitted through the prescribed manner could be entered into the electronic grade book. Once the students understood this course limitation, they became more adept at using the assignment area to submit their documents.

The importance of timely instructor-tostudent feedback cannot be over-emphasized. Student-to-student interaction is also critical in order to minimize what David Beckett calls "disembodied learning." Since the majority of communication is via the bulletin boards and electronic mail, the student may at times feel isolated. ${ }^{8}$ Students are encouraged to actively participate in the course forums, and their level of participation forms a part of their grade. Nevertheless, some students may lack motivation or feel inhibited and limit their responses. The instructor must guide the discussions so that all will derive benefit. The use of "open" chat sessions on a weekly basis can help to alleviate some of these concerns, as it allows for a freedom of expression that cannot be achieved using other means.

\section{Instructors' Challenges and Self-Evaluation of the Course Experience}

The issue of integrity and assessment of student learning is at present one of the most challenging ones. Since Internet applications do not allow professors to identify users, it is impossible to be sure that students are completing the course assignments themselves. In our opinion, the integrity and the fairness of the teaching and learning process were maintained in our course. We had the ability to evaluate student participation not only by means of the final exams and the assignments, but also via the bulletin boards and the monitoring of the web activity through the WebCT hitcounting functions. For us it rapidly became evident which students were having difficulty with the course or who lacked the motivation necessary for distance learning.
The virtual classroom creates new faculty roles (content designer, discussion mediator, technical advisor) and places new and sometimes unexpected demands upon the instructional staff. Since one of the most important aspects of the teaching model is the interaction between students and the instructor, the latter must be fully committed to maintaining open channels of communication. If students begin to feel lost or uncomfortable, then the major benefits of online teaching are rapidly diminished: the professor must be constantly vigilant, examining the students' responses, levels of participation, and comments. Some of the students may require more orientation to the technical aspects of the course, and it is the responsibility of the instructor to provide this assistance. It is to be hoped that as more courses become available online, there will be an increasing number of students who can perform as "peer tutors," thereby increasing the sense of community that can be achieved by the group.

In future courses we plan to implement a combined teaching strategy that will improve our communication methods: a group project accompanied by a reflective journal. The group project will build an opportunity for cohort learners' interaction, beyond the already discussed chat rooms, forums and e-mail. The group task will be the translation of a medical research article in groups of 3 to 5 students and it will involve: (1) reading and discussing the theoretical studies written on this topic (Newmark, Pilegaard and Williams); (2) journal keeping in order to reflect upon the problems posed by the translation and the different methods utilized to reach solutions; (3) translation of the article. Team translation is a valuable technique that is used by professionals for large translation projects with ever-increasing frequency. The WebCT platform conveniently allows for the separation of students into presentation groups, whose completed work can be easily viewed by the entire class. Group work is facilitated by the assignment of a group e-mail address, which streamlines communication between members. The pedagogical advantages of this project derive from the fact that students will focus on the translation process, rather than the final results. The students will not only have to present their translation choices, but also to defend them. In the web-based environment this type of interactive project will mitigate the isolation syndrome that, in our opinion, is the main challenge for student motivation.

\section{CONCLUSIONS}

The skills that our translation students are required to possess nowadays in order to assure a successful entry into the workplace involve new teaching and 
learning approaches. In the curriculum development of our Medical Translation course we focused on linguistic, practical, pedagogical, and psychological aspects related to self-directed learning. Our experience has taught us that distance education does not have to be synonymous with unconnected, solitary, or (dis)located teaching, learning and research. ${ }^{9}$ The percentage of online classes remains small, and we still have much to learn about the teaching-learning process that occurs with web-based delivery of instruction. Only time can tell us about the fate of distance education in the future. ${ }^{10}$ Whether it becomes the dominant form of instruction delivery or whether it is doomed to fail, it is providing us with an excellent opportunity to reflect upon our teaching techniques, both in the traditional and the web environments.

María Asuncion Gómez and Steven Weinreb Florida International University, Miami, United States

\section{NOTES}

1. Not all educators and researchers agree with the euphoric reactions that most have in regard to technology. Bulik warns us that potential and reality are not always synonymous: "The U.S. Department of Commerce (1999) survey on Internet use concluded that, far from democratizing education and enhancing access to resources, this technological revolution is bypassing the poor, minorities, those who live in rural or inner city communities, and those over the age of fifty-five" (18).

2. Research on self-directed learning (SDL) is growing and a sign of its importance in the field of adult education is the annual symposium devoted exclusively to (SDL). For further information, see Bulik, Long and Houle.

3. At the professional level, one of the most active international online forums in the field of Medical Translation is MedTrad. Since there are certain restrictions to become a member of this listserv, the students will not be able to participate in it. However, the class forum will try to emulate the kind of professional discussions that take place in the "real world" of medical translation.

4. WebCT can also be used as an auxiliary tool that complements standard classroom-based instruction. In the "web-assisted" mode, the instructor utilizes the course web pages and discussion boards to post information, syllabus material, and readings, but students are expected to attend regular classroom sessions. In our case, students were only required to take a final exam in a monitored environment. This exam is given on the university campus, but the Distance Learning Office can make arrangements with other institutions (community colleges, universities, public libraries, etc.) in order to accommodate those students who live too far from the campus.
5. At our institution most of the instructors who utilize WebCT have attended online teaching seminars offered by the Instructional Development Center. Although it is possible to design a course without the benefit of the seminars, most instructors have found that attendance greatly accelerates their own learning time and allows the course to be developed within weeks rather than months.

6. The pages must be uploaded to the WebCT server in HTML format.

7. See David Beckett's "Disembodied Learning: How Flexible Delivery Shoots Higher Education in the Foot: Well Sort Of."

8 Many educators have considered the challenges of distance learning instruction. For insights on this matter see McVay's How to Be a Successful Distant Student: Learning on the Internet.

9. See Usher and Edwards' "Lost and Found: 'Cyberspace' and the (Dis)location of Teaching, Learning and Research."

10. Robin Dasher and Gerald Patton are not very optimistic in this respect. They believe that the dominant form of instruction will always be the traditional face-to-face classroom.

\section{REFERENCES}

Beckett, D. (1988): Disembodied Learning: How Flexible Delivery Shoots Higher

Brookfield, S. (1993): Self-directed Learning, Political Clarity and the Critical Practice of Adult Education. Adult Education Quarterly 43, 22742.

Bulik, R. (2000): Issues, Challenges and Changing Metaphors: Teaching and Learning in the Virtual Classroom. FIU Journal for the Art of Teaching 7,1, 17-34.

Dasher-Alston, R. \& G. Patton (1988): Evaluation Criteria for Distance Learning. Planning for Higher Education 27,11-17.

Education in the Foot: Well Sort Of. Electronic Journal of Sociology 3,3. Available online: http://www. sociology.org/content/vol003.003/beckett.html

Houle, C. (1984): Patterns of Learning: New Perspectives on Life-Span Education. San Francisco, CA: Jossey-Bass.

Hurtado Albir, A. (1993): La didáctica de la traducción. In Le Masque et la plume. (ed. Edith Le Bel) pp. 65-92. Seville, Universidad de Sevilla.

Keating, A. and J. Hargitai (1999): The Wired Professor. A Guide to Incorporating the World Wide Web in College Instruction. New York: New York UP.

McVay, M. (1998): How to Be a Successful Distant Student: Learning on the Internet. Needham Heights, Simon and Schuster.

Usher, R. and R. Edwards (1998): Lost and Found: 'Cyberspace' and the (Dis)location of Teaching, Learning and Research. Paper presented at the 28th Annual SCUTREA Conference, U of Exeter, UK. Available online: http://www.leeds.ac.uk/ educol/documents/000000742.doc 